\title{
Strategy: Can a Research Methodology Be Proposed from Islamic Sources of Knowledge?
}

\author{
Waseem Gul ${ }^{1}$ \\ ${ }^{1}$ MBA, MSc, SLA Management (ICT Solutions), Oman Telecommunication Company (S.A.O.G) PO Box 789, \\ PC 112 Ruwi, Sultanate of Oman \\ Correspondence: SLA Management (ICT Solutions), Oman Telecommunication Company (S.A.O.G) PO \\ Box 789, PC 112 Ruwi, Sultanate of Oman.
}

Received: May 6, 2019

doi:10.5539/ibr.v12n7p83
Accepted: June 17, $2019 \quad$ Online Published: June 18, 2019

URL: https://doi.org/10.5539/ibr.v12n7p83

\begin{abstract}
The study has attempted to propose a research methodology for the subject of strategy from an Islamic perspective. It employed qualitative research methodologies to explore and analyze the content taken from the texts of the Quran and the Hadith; the Islamic Law contained in these texts; interpretation of this law via Islamic Jurisprudence. It has argued to extend this law into multiple layers of the research methodology ensuring whole research cycle takes place within the Tawhidic Paradigm propounded in the texts of the Quran and the Hadith. In doing so, it adopted the model of the research methodology as developed in the Jeudo-Christian or the Western cultural context and tried to replace the research philosophy(es) and reasoning approaches with the Islamic Law and Islamic Logic, enabling the whole methodology to operate within the framework of revelation and human reason at each and every layer and every aspect.

This study is a part of the efforts which are being made to explore alternate perspectives in order to overcome the prevailing issues emerging in the classical management theory and practice, including those related to strategy. While works of scholars from cultural contexts different from the western cultures are surfacing in this area, it seems to be useful to also explore the Islamic sources of knowledge for the very purpose. It is to highlight a crucial point that this study should not be considered a way of negating or rejecting the existing body of knowledge, but it is an attempt to bring something which may complement it or provide a new way of looking into the subject of strategy.
\end{abstract}

Keywords: civilization, culture, Jeudo-Christian, Islamic, jurisprudence, worldview, theory, strategy, methodology, revelation, reason

\section{Introduction}

\subsection{The Study and Its Objective}

The study is aimed at exploring the Islamic sources of knowledge and seeking the possibility of existence of a research methodology for the subject of strategy from an Islamic perspective. While a huge knowledge bank explaining multitude of aspects about Islam and its principles etc. is available with all the ease, it is acknowledged here that the way it is presented to the world seems to be incompatible with the contemporary world of human thought and practice. But is it really incompatible in its essence? This is the question that has driven the need for current study. This is the first of its kind as no previous literature of the similar sort could be found, as focused on the research methodology for the subject of strategy, even after employing the best efforts, especially in English language. Being so, it looks into the Islamic sources of knowledge and explores how a Tawhidic Paradigm gives birth to an Islamic culture or civilization comprising of various layers, i.e., belief system and laws etc. that operate to drive an Islamic culture. Knowledge and production of knowledge is the spirit of a society that keeps it alive and moving. Same is the case with the Islamic society and culture. The study seeks the Tawhidic Paradigm as presented in the Islamic sources of knowledge and traces its impact, or spirit so to speak, operating down the layers of a research methodology such as the research philosophy(ies), approach(es) till the practical design and its execution etc. In this pursuit, it dives into Islamic sources of knowledge and then leverages the prevailing body of knowledge in the Western realm to propose a research methodology for this specific area of social sciences, i.e., strategy. Also, it sets certain conditions which should be met by the new research methodology in order to stay within the framework of the Islamic Laws as entailed in the revealed texts on one hand while being robust enough to be 
accepted as a valid methodology by researchers and practitioners.

\subsection{Significance of the Study}

Kazmi $(2003 ; 2005)$ realized the need for alternative approaches, other than those born and brought up in JeudoChristian cultural contexts, to management research and practice; and presented a research direction in order to explore management concepts from an Islamic perspective and to investigate if they are workable? He suggested to focus on investigating into the paradigms of conventional management, and for comparing and contrasting them with what the Islamic approach to management has to offer. The purpose being not to criticize the conventional approach(es), but to offer new insights into what could possibly be wrong with those approaches and how those could be corrected, i.e., a complementation attempts rather than confrontation among the conventional and alternative approaches. This approach could lead to address the universal concern for utilizing human ingenuity in order to manage organizations effectively.

Kazmi (2003) fully understands the need of availability of purposeful qualitative work which could become a fountainhead of meaningful quantitative research but which is missing at present. The available work is descriptive and not analytical, thus does not propagate further research work. He points to a superficial stream of behavior among Muslim scholars who keep trying to tell the world that existing conventional theories or postulates are nothing new and that these were already there in the Islamic realm of knowledge. Such approaches may console Muslims; however, it poses a dangerous threat of diversion from what should actually be done. And it is very true that less attempts have been made to link the teachings of Islam to the modern management practices, including strategy, employing analytical tools and techniques. To fill this gap, Kazmi encourages the management researchers to explore the field of management from an Islamic perspective and provides them with an extensive and comprehensive proposal for research that is comprised of four streams, i.e., "dig the gold", "chinks in the armor", "delve deeper" and "hands-on" approaches. This proposal can be considered as an important milestone towards viewing the management concepts from an Islamic perspective as it insists on a wider and deeper theoretical and empirical study on which he himself has embarked on (Kazmi and Ahmed, 2006). This is something quite different from existing practices that prevail among Muslim scholarship, as already mentioned.

Recently, Zandi et al. (2015) responded to this need and proposed an extensive empirical research plan which is aimed at finding the strategies of Muhammad PBUH that he adopted during his lifetime, especially those adopted during wars or battles, to see how they are being employed in current day business as well the outcome of the implementation of these strategies. This research is intended to be conducted in selected organizations in Malaysia. It seems to be an important step, if taken, towards research in this area from an Islamic perspective. Gul (2016) considered it to be valuable if an effort is made to first identify the concept of 'Strategy' within the Islamic sources of knowledge, comprehend it within the Islamic world-view, make comparisons with the same concept available in other world-views and then proceed for further theoretical and empirical research.

Current study is one such effort to explore the research methodology for strategy and the possibility of theory building and testing in this domain. Such study does not seem to exist after best effort was employed to search for that. The study, thus, is an attempt to fill this gap while adopting one of the four approaches proposed by Kazmi (2003), i.e., the "dig the gold approach". This approach means a straightforward manner of looking into the Islamic sources of knowledge and their interpretations etc. for nuggets of wisdom to be brought to light through individual or collective effort and is taken up by current study.

Other approaches are not touched here at all. This study, together with other studies, is expected to help avoid the same wrong which Muslim scholars have been committing of superficially announcing different terminologies and concepts to be similar to those emanating from Islamic sources without going deeper into the world-views, these come from and their implications in the philosophical and practical worlds.

\subsection{Scope of the Study}

The research methodology of a subject is an overall framework of principles which a researcher follows to investigate into the truth of concepts, theories and basic principles of reasoning of that specific subject. Current study provides an introduction to the research methodology for strategy as it prevails in the Western or the Judeo-Christian cultural realm, reviews Islamic sources of knowledge and tries to see if there exists or may exist some sort of research methodology from Islamic perspective as well? In this pursuit, the study delves into a variety of sources such as the concept of strategy as it springs from the Western cultural context; the cultural context itself; philosophies which prevail in these cultures; and its underlying assumptions as core values that drive organization and management practices (e.g., strategy, strategy formulation and implementation, and strategic decision making process etc.); and then the research methodology for the subject of strategy. Taking 
into account that the concept of strategy exists in Islamic sources of knowledge (Gul, 2016), current study embarks to bring to fore the architecture of an Islamic cultural context; the themes that shape such a culture; and the assumptions as well as the core values that should drive theory and practice in the field of organization and management. Finally, it discusses the viability of the methodology for the subject of strategy form Islamic perspective and then makes conclusions for further elaborations, testing and implementations of the methodology in real time scenarios.

This study contents itself to introducing briefly the methodology for strategy in the Western context to let the reader have a review of the theme. It then proposes the methodology from Islamic perspective. It doesn't touch aspects such as comparisons between methodologies coming from different cultural contexts such as Indian, Chinese or any other civilizational or cultural contexts. Practical implementation of the proposed methodology and its testing is left for a separate study. Also, it doesn't delve yet on how effective or ineffective the proposed methodology of strategy could be, if one may exist at all. Lastly, the probable conditions such as the presence of an Islamic state is left for further research.

Since the intention is only to provide a new view of theory building, theory testing and model building; the study avoids as much criticism of existing methodologies as possible and focuses only on providing an introduction of a methodology from the Western perspective and then moves forward to propose one from Islamic perspective. Put, simply, this study is dominantly of a descriptive nature prescribing a new way of looking into the subject matter.

\section{Literature Review}

\subsection{The Concept of Strategy and Research Methodology}

The concept of strategy has been conceived in numerous ways by different researcher and practitioners (Gul,2016). Seemingly, the concept of strategy emerges in the shape of a coherent combination of objectives (ends, purposes, goals, competitive priorities, etc.) and actions (means, policies, plans, activities, etc.) required to achieve those objectives. Objectives relate to how an organization intends achieving these ends. This was realized by Kazmi (2008) who attempted to conceive strategy in a quite simple but comprehensive manner. He states:

"The term 'strategy' is derived from a Greek word strategos, which means generalship---the actual direction of military force, as distinct from the policy governing its deployment. Literally, therefore, the word 'strategy' means the art of the general. In business parlance, there is no definite meaning assigned to strategy. It is often used loosely to mean a number of things.

- A strategy could be a plan or course of action or a set of decision rules making a pattern or creating a common thread;

- The pattern or common thread related to the organization's activities which are derived from the policies, objectives and goals;

- Related to pursuing those activities which move an organization from its current position to a desired future state;

- Concerned with the resources necessary for implementing a plan or following a course of action;

- Connected to the strategic positioning of a firm, making trade-offs between its different activities and creating a fit among these activities; and

- The planned or actual coordination of the firm's major goals and actions, in time and space that continuously co-align the firm with its environment.

In simplified terms, a strategy is the means to achieve objectives. In complex terms, it may possess all the characteristics mentioned above. With so many different interpretations of a term, it is really difficult to fathom what strategy really means. This is understandable. Yet we need to consider all these interpretations at once. This diversity of interpretations gives us valuable insights into what thinkers and writers have proposed from time to time. With the wealth of understanding we have at our command, thanks to the intellectuals who have contributed to creating it, we can broaden our thinking."

Having conceived 'strategy' as a concept, next is to introduce what is research methodology prevailing in this important area of organization and management.

'Strategy' as body of knowledge, or a social science to be a more specific, was developed in the Western cultural context and has captured the attention of organization and management researchers since its inception. Those 
interested in this area are suggested to review the works of Kuhn (1962), Burrell and Morgan (1979), Sutton and Staw (1995), Weick (1996), March (2007), Miller (2008). Like other areas of organization and management, the research in this area has the same purpose when it comes to the methodology, i.e., to understand organizational phenomena and developing recommendations for managerial action (Ketchen Jr., Boyed, Bergh, 2007). Methodology investigates into the truth of concepts, theories and basic principles of reasoning in a specific subject area under consideration. In simple terms, it deals with the source(s), nature and development of knowledge in order to determines the roadmap towards understanding certain phenomenon. It accomplishes so through defining ways in which data is collected, analyzed and used. Moreover, it also sets standards for the acceptability of evidence and determines the role of reason in the investigation within a certain paradigm or philosophical framework.

Like almost every other area of social research, there could be a wide difference of opinions on the methodology for strategy as well. These differences may arise at any level of the methodology, i.e., the paradigm, the philosophy, the approach, choice of methods down to the data collection and data analysis levels as represented in the Research Onion (Saunders et. al., 2009) as shown in figure below:

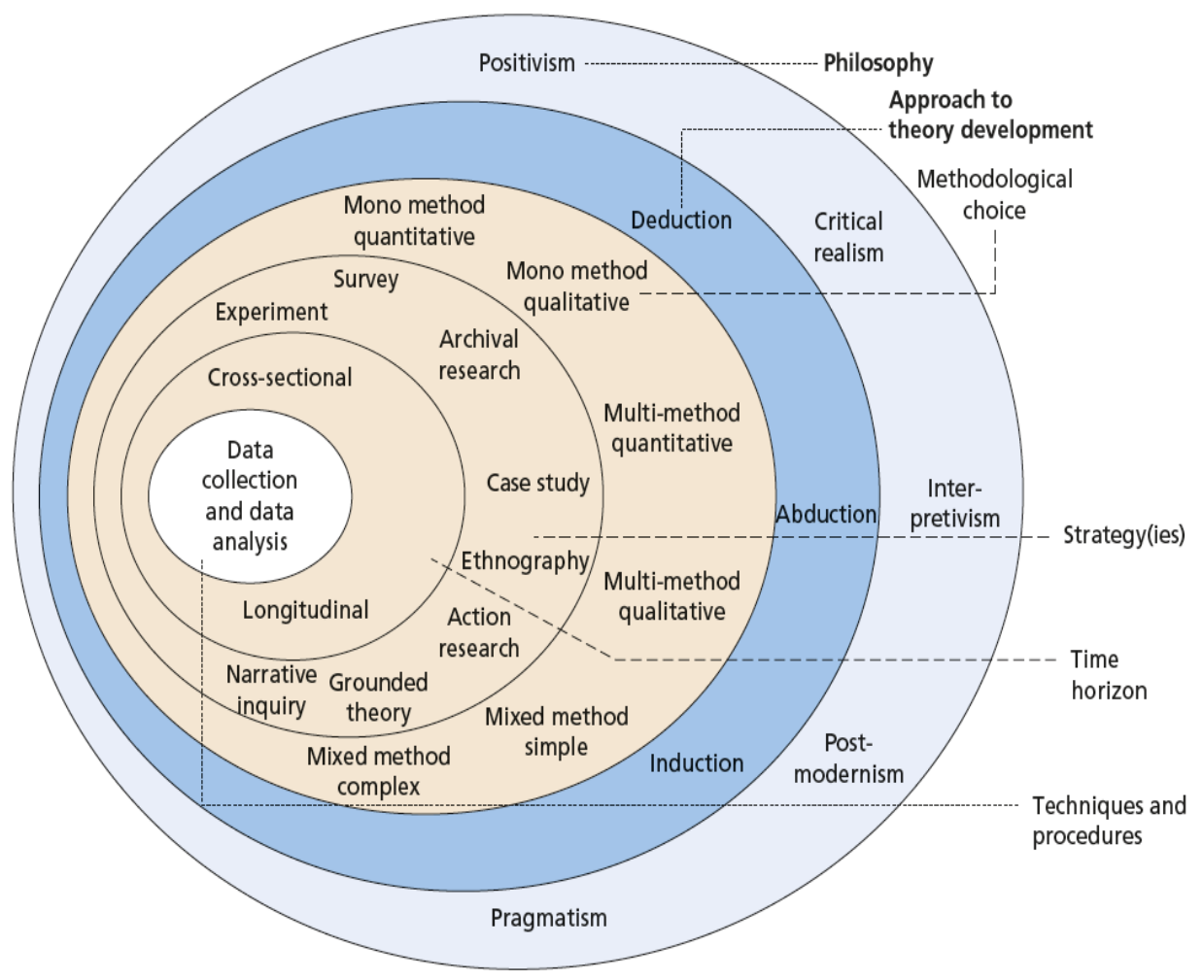

Figure 1. The Rearch Onion in Western Cultural Context

Researchers have taken varying positions in their choices at every layer of the research onion, and often heated debates have ensued as a result. Methodology is necessary to lay down the foundations of a specific body of knowledge and to develop it over time. Without a clear methodology, data and information may not be taken a serious affair (Crotty, 1998). It is notable that all these different layers of methodology are, in different ways and to different extents, connected with each other and the choices made at one layer would arguably impact the choices at the other layers. These layers operate in a coherent and synchronized manner to let the research activity reach some conclusions.

It is important to mention here that the researchers are keen to build theories, reach the truth of the existing theories, model building, implementations, probable outcomes or relevance to the real-world scenarios etc. Additionally, and interestingly, each methodological approach would claim to reach the truth in a surer manner as compared to others. This is indicative from the variety of perspectives about almost every concept in the realm of organization and management, and also for the concept of strategy. Man is, in fact, keen to reach the truth in every possible domain of knowledge and the debate on methodology is an inborn human trait which is reflected at times. In this whole discussion, there should arise an extremely important question: What paradigms or philosophies drive research methodology in the Western cultures? 
In order to answer this crucial question, it is imperative to understand what constitutes a cultural fabric? how these constituents interact with each other? how and to what extent these impact the overall fabric? how a paradigm or philosophy is oriented in the culture? How these paradigms and philosophies drive the research activity in various areas of social sciences? etc. Nieto (1999) has provided a very good view on this. He states the important role of the system of values, traditions, social and political relationships, and world views created and shared by a group of people bound together by a combination of factors that can include shared history, geographic location, language, social class, and/or religion, and how these are transformed by those who share them. In everyday social setting, we use culture to express and give meaning to our identity which in turn is used to construct affiliations with and boundaries between other individuals and groups. The Western cultures exhibit the same anatomy, essentially impacted by various streams of Greek and Roman philosophies, the psychological impacts of the Dark Ages, the Renaissance, the Reformation, the Enlightenment and, of course, Christian and Jewish religious texts and practices etc. There are certain paradigms and philosophies operating in these cultures that emerged over time, most dominant of which are the Liberalism, the Secularism etc. which serve as paradigm of thought and action to cope with the most part of the living issues in those cultures. The research philosophies such as the Empiricism, the Realism, the Post-modernism etc. are hosted in these cultures which, together with the paradigms, drive the research activity in natural as well as social sciences including the subject of strategy. Researchers engaged in the area of strategy follow, in general, the same set of ontological, epistemological and axiological assumptions as suggested by such paradigms and philosophies.

From the Research Onion as provided in Figure 1, it is apparent that a standard research methodology should have:

- A paradigm or research philosophy (to set fundamental assumptions)

- An approach to theory development (logic and reasoning used for argument)

- Methodological choice (selection of adequate type of method)

- Strategies (choice of research execution strategy)

- Time horizon (the choice of depth and breadth of investigation)

- Techniques and procedures (tools and techniques employed for calculations)

Having mentioned that there exists a structured research methodology for strategy from the Western cultural context, it is also acknowledged that the author couldn't find any such methodology for the subject area of strategy from an Islamic perspective. Though works could be found in the areas of social sciences such as economics, law, history, sociology, political science and to some extent management etc. but a structured research methodology for strategy couldn't be found. While reviewing Islamic literature, only the teachings, laws and principles about various affairs of life could be spotted. It is argued that the positive aspect of such teachings, laws, principles is that there is a possibility to synthesize and extend these in order to propose a research methodology in a specific area of social sciences.

\section{Methodology}

\subsection{Data Collection}

Documents have been used as sources of data since the nature of study benefits from a number of knowledge streams. The term 'document' covers a very wide range of different documents entailing data available for acquiring, analyzing and assembling. It includes the Quran, the books of the Hadith, Islamic Jurisprudence etc., literature on the Western philosophy and culture, organization and management (specifically the subject of strategy) etc. Bryman and Bell (2007) recommend the criteria of acceptable documents with the certain traits, i.e., can be read, has not been produced specifically for the purpose of research, is preserved to be available for analysis and is relevant to the concerns of the researchers in the business realm. It is argued, here, that Islamic sources of knowledge and the knowledge obtained from these do qualify these criteria. Rest of the data, i.e., about the Western culture or civilization, the philosophies, the economics and strategy qualify for the same.

Qualitative data includes literature on the concept of strategy highlighting the variety of standpoints about it, the methodologies involved, the architecture of the Western culture from which this methodology (or methodologies) springs out, and the paradigms which govern the respective methodologies etc. The data extends to include literature from Islamic perspective to assess and analyze, step by step, and see if there exists (or may exist) a methodology for strategy from an Islamic perspective.

\subsection{Methodology Used}

Choice of methodology plays vital role in research design. It is the overall configuration of a piece of research involving questions about what kind of evidence is gathered and from where, and how such evidence is 
interpreted in order to provide good answers to the initial research question, adoption of adequate research strategies and methods, data collection and analysis etc. (Easterby-Smith et al., 2012).

Due to conceptual nature of the study, inductive approach has been adopted within largely an interpretivist philosophical paradigm. For this purpose, a combination of qualitative methods recommended by 'Grounded Theory' and 'Narrative Inquiry' is employed. The goal is to avoid as much pre-judgement or bias as possible, and to go in with an open mind to see what emerges/is grounded in the data alone, i.e., it has not been informed in any way by pre-existing hypothesis. The concept of 'Hermeneutics', 'Phenomenologists', 'Symbolic Interactionism' operate in current study since it looks into the data sources (documents, lived experiences, emerging patterns etc.) and leads to an understanding of social worlds and contexts. Complying with the requirements of such study, a good study of various sources, i.e., the Western as well as the Islamic, was conducted. This helped to identify certain patterns of cultural architecture in both the contexts and also the respective underlying assumptions that operate in those cultures and shape activities at group level (institutions, organizations, firms etc.). Seeing that a research methodology for strategy emerges from Western cultural context, an attempt has been made to propose possibility of a methodology in the Islamic cultural context as well. Apparently, it seems similar to 'Pattern Matching' approach but it turns out to be different if seen carefully as it doesn't make any presumptions or hypothesis before embarking on the study or analysis which are a necessary part of the pattern matching approach.

To ensure the study stays within reasonable limits of length and breadth of time, while trying to go into a good level of depth, references to Western philosophy have been made and presented very briefly, though concisely. It is notable that due to the descriptive nature of the data, only concepts can be derived from the emerging patterns and not necessarily the numbers. Validity has been ensured by introducing a coherent and synchronized presentation of the concepts as these emerge from their respective sources and synthesize to produce some legitimate outcome.

\section{Findings and Discussion}

It is useful to move from known to unknown while delving into something new. A research onion was introduced in section 2.1 which provides information about how a research methodology from the Western perspective works when employed in a certain subject area. The fact of the matter is that the research methodology for strategy is a well mature art or science; it operates on well-defined paradigms and philosophies; it is driven by specific assumptions; the choice of approaches is fully known and so on with every layer of the research onion. Author of this study considers to follow the same model to propose a new methodology instead of reinventing the wheel. However, it is done introducing the concept from the Islamic sources of knowledge as the basis for research methodology and a research onion that operates on the principles laid down in these sources.

Thus, the study has tried to bring to fore the concept of strategy, the methodology for strategy, and a brief introduction to the fact that these took birth and grew up in organization and management realm of the Western cultures, as they operate on the paradigms and philosophies prevailing in those cultures. It is time now to provide the findings from the study of Islamic sources of knowledge (the Islamic Law; its interpretation and extension) to explain if a research methodology could be proposed from the Islamic sources of knowledge as well?

\subsection{Some Basic Themes}

It might be useful to provide scholars, especially the non-Muslim ones, with some basic introduction to the themes and the terms related to this study:

- From an Islamic perspective, the divine revelation is the source of all knowledge (Azram, 2011). This revelation is the Quran (Al-Quran) which was revealed to Muhammad PBUH who, under the guidance of the

God, practically modelled the principles of the Quran. This practical modelling of the Quranic principles by Muhammad PBUH is called the Way or the Sunnah (Al-Sunnah). Thus, the two primary sources of knowledge in Islam are the Quran and the Sunnah of Muhammad PBUH.

- Muslims use the word the God (Allah) for the supreme being Who is the Creator (Al-Khaliq), the Absolute Authority (Al-Malik), the Omnipotent (Al-Qadir), the Omniscient (Al-Knowing) etc.

- Quran is divided, based on different topics, into 114 Chapters (Surah) of unequal size where each chapter is comprised of multiple Verses (Ayat). The Sciences of the Quran (Ulum al Quran) refers to the knowledge necessary for the interpretation, known as exegesis, of the words/verses in Quran (Denffer, 1994).

- The reports about the statements, the acts or the silence about a matter by Muhammad PBUH are called the Hadith (Al-Hadith), narrated by his Companions and transmitted through generations. Hadith, when studied 
by employing a specific technical knowledge, called the Sciences of the Hadith (Ulum al Hadith), provides information of the Sunnah of Muhammad PBUH (Philips, 2007).

- Islamic sources of knowledge entail the Islamic Law (Shariah) in the form of texts. This law springs out of the Quran and the Sunnah and shapes a specific world-view known as the 'Islamic World-View', i.e., how Muslims should see the world inside and around them? How should they deal with the different affairs of individual and collective life? What are the obligations and rights, good and bad, right and wrong, permission and prohibitions, rewards and punishments etc. The knowledge of the Islamic Law is covered under the name of the Islamic Jurisprudence (Fiqh), the principles applied to understand this law as 'Usul al Fiqh' and the efforts applied for this purpose are termed as 'Ijtihad'. The one who conducts Ijtihad is the jurist (Mujtahid) and the one who follows him is known as the follower (Muqallid). When the term Islamic Jurisprudence is used, it actually means Islamic texts and the law contained in these text.

- Muslims use PBUH (Peace Be Upon Him) for every prophet to show respect without any discrimination, hence they use it for Adam, Noah, Solomon, David, Abraham etc., also they do the same for Muhammad PBUH. The plural to this term is PBUT (Peace Be Upon Them).

\subsection{Architecture of an Islamic Culture}

Maududi in one of his classics "Islamic Civilization: Its Foundational Beliefs and Principles" provides a simple, but extraordinarily comprehensive, manner about what Islamic beliefs and principles are, and how they operate in individual as well as collective spheres of human life to shape an Islamic society which, in turn, exhibits an overall culture or civilization. With the aid of the two other very important works of Nyazee "Islamic Jurisprudence" and "The Theories of Islamic Law", his ideas can be summarized in a layered hierarchical model as below:

1- Islam reminds humans about the existence of one true God (Allah) Who is Al-Khaliq and created whatever humans know or they don't. He is Al-Malik Who owns everything and that every being has to return to Him after spending certain span of time in this world and face Him on the day of the judgement (Al-Akhirah) for the accountability of whatever they did in their lives on earth. He is Al-Alim Who has the knowledge of each and every thing, e.g., the past, the present and the future; what's good or bad; what's right or wrong for His creatures including human race. This forms first and the most important layer in the hierarchy of Islam and is termed as the Oneness of God (Tawhid) or the Tawhidic Paradigm.

2- The true and the exact knowledge about Allah is passed on to humans via the Messengers (Rusl; sing: Rasool) i.e., chosen ones from humankind. These chosen ones received revelation from Allah, during their lifetime on earth, through the Angel Gabriel and guided humankind in the light of the revelation (Wahy). Together with belief in Allah and the day of judgement (Akhirah), belief in the Messengers, the Angels and the Books form five fundamental beliefs of Islam. This set of beliefs is the offspring of the Tawhidic Paradigm.

3- This Towhidic Paradigm leads, by operationalizing the fundamental beliefs, to establish a specific worldview known as the Islamic World-view, i.e., how Muslims should see the world inside and around them? How should they deal with the different affairs of individual and collective life? What are the obligations and rights, good and bad, right and wrong, permitted and prohibited, rewards and punishments etc. This worldview is an arbitration of the Islamic Law (Shariah).

4- Muslims when come together to form a society, their world-view is reflected in their individual and collective life generating a particular set of beliefs and values. They are required to theorize various concepts, build theories and design models, and then based on these theories and models realize and utilize various systems, e.g., political, educational, economic, judicial, healthcare systems etc. This is aimed at enablement of the society in a pattern desired by Allah and guided by His Messenger, Muhammad (PBUH), being the final one in the chain of the messengers initiating from Adam and extending from Noah, Abraham, David, Moses, Jesus (PBUT) to mention a few among many, the knowns as well as the unknowns.

5- These systems, rooted in the same paradigm or sources, operate in coherence and synchronization with each other to achieve the same ultimate objectives, generally known as Higher Order Objectives of Shariah or simply the purpose of Islamic Islamic Law (Maqasid al-Shariah) as well as employing the idea of the interest (Maslahah) in varied time-space-people situations requiring varied interpretations of the law. These objectives, at high level, include the protection and growth of belief, life, intellect, race, wealth of those who constitute the Islamic society.

It is essential to understand that ideally each and every layer is connected with each and every other layer above and 
below itself, affecting each other positively or negatively, depending upon the accuracy or inaccuracy of the thought or actions or the operational conduct (somehow similar to the cogs of a machine). Thus, it is impossible to see these layers in an isolated stand-alone status. This means the Tawhidic Paradigm drives the whole machine by providing a framework of operation, i.e., the Islamic Law interpreted through the Islamic Jurisprudence. This framework operates on two planes, i.e., a Fixed Plane and a Variable Plane (To be discussed in next section). A society in which Tawhidic Paradigm is the engine is called an Islamic Society and its ultimate manifestation occurs in the form of an Islamic Civilization. Any culture with Islamic civilization as its core is termed as an Islamic Culture.

This is to say that there exists a very clear and well-structured architecture of an Islamic culture. One may think if this Tawhidic Paradigm is the only engine which moves the overall Islamic culture or civilization? What about other factors such as race, language, customs etc.? In fact, all these factors also play a very important role in shaping an Islamic culture, however these should always remain sub-servient to the Tawhidic Paradigm.

Now is the time to argue that if a methodology is proposed in such a cultural context, it will take its basic assumptions from Islamic sources of knowledge and operate to reach the reality.

\subsection{Proposing a Research Methodology for Strategy from Islamic Perspective}

Considering the architecture of an Islamic culture as explained in section 4.2, the research methodology should also be hosted by the same layered model like any other activity in an Islamic culture. Thus, it is argued here that:

- The Tawhidic Paradigm, as manifested in the Quran and the Sunnah, serves as the research paradigm and the Islamic Law as the research framework or research philosophy.

- The approach to theory development, i.e., logic and reasoning stay subservient to the Tawhidic paradigm and is moderated by Islamic Law through Islamic Jurisprudence.

- Then subsequent layers of the research onion should operate in tandem with the layers above them.

In fact, these are the most important layers, i.e., research philosophy and approach(es) to theory development. Subsequent layers are moderated or orchestrated by these two layers. Therefore, the first and the foremost requirement being the availability of a research paradigm; a world-view or a philosophy (or philosophies) and a set of approaches is fulfilled by the Tawhidic paradigm or Islamic Law and Islamic logic to build a new methodology.

According to this argument, the proposed Research Onion would look like as drawn below:

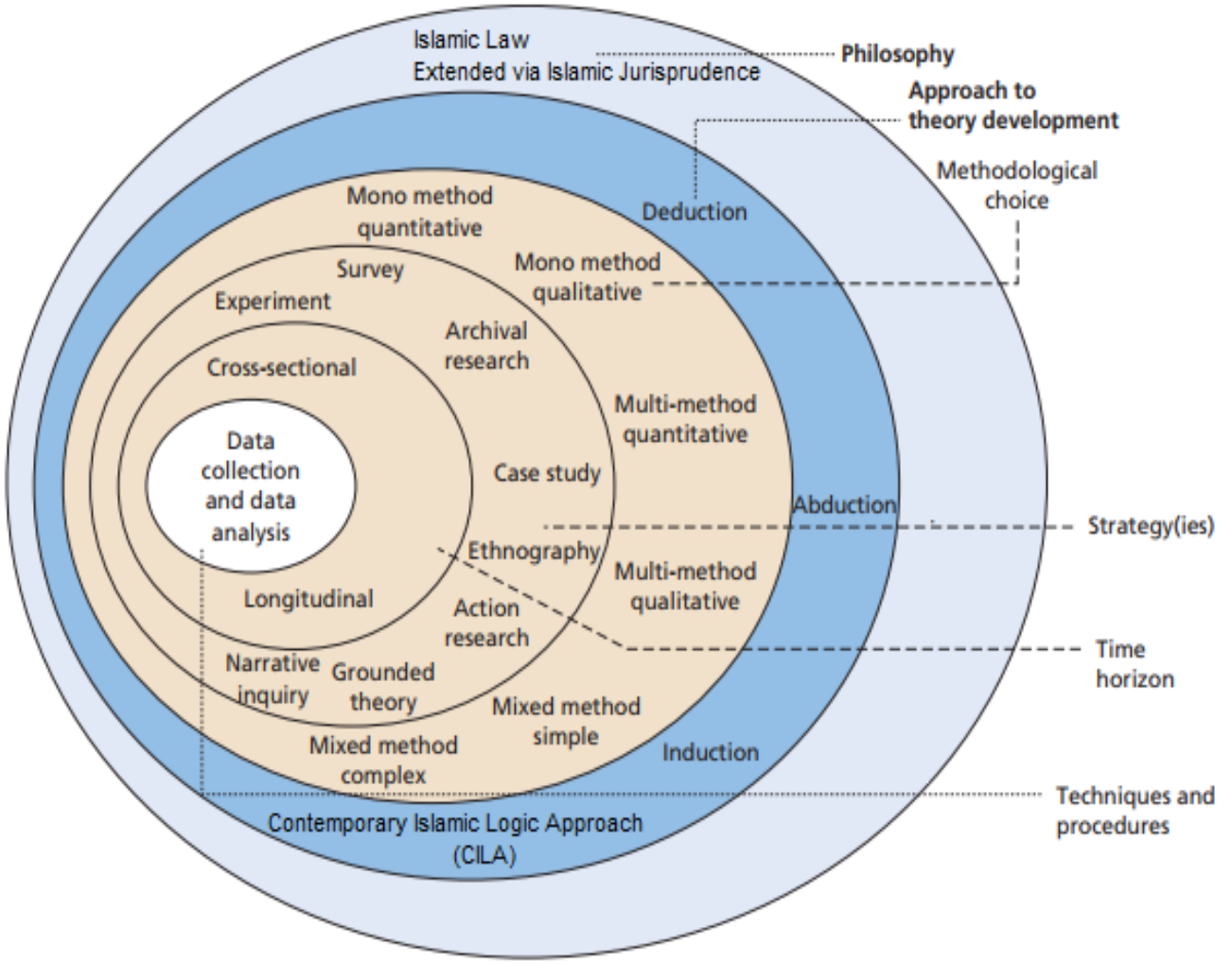

Figure 2. The Rearch Onion from Islamic Perspective 
But how this paradigm and the philosophy would operate in a social scienc such as strategy to build or test theories and to design models?

To proceed and answer this question, it is imperative to provide again a brief introduction to an extremely crucial area of technical knowledge, termed as the Islamic Jurisprudence:

Islamic sources of knowledge entail Islamic Law (Shariah) in the form of texts. This law springs out of the Quran and the Sunnah and shapes a specific world-view known as the Islamic World-view, i.e., how Muslims should see the world inside and around them? How should they deal with the different affairs of individual and collective life? What are the obligations and rights, good and bad, right and wrong, permissions and prohibitions, rewards and punishments etc. The knowledge or the understanding (Fahm) of the Islamic Law is covered under the name of Islamic Jurisprudence (Fiqh), the principles applied to understand this law as Usul al Fiqh and the efforts applied for this purpose are termed as Ijtihad. The one who conducts Ijtihad is the jurist (Mujtahid) and the one who follows him is known as the follower (Muqallid). The jurist identifies the law, applies it to the known situations and extends it to the situations which are not covered previously but are similar to the previous ones employing specific techniques known as Analogy (Qayas). In conclusion, the jurist provides a framework to deal with the real-life experiences which operates according to a defined set of rules or theories keeping in consideration the Higher Order Objectives of Shariah (Maqasid al Shariah) as well as employing the idea of the interest (Maslahah) in varied time-space-people situations requiring new interpretations of the law. It is this technical area of which requires to be operationalized in a manner that it serves, practically, to orchestrate different layers of the research onion.

It is argued that the Tawhidic paradigm or Islamic Law, interpreted and extended via Islamic Jurisprudence, would enable the research methodology. However, the question arises how this methodology could be operationalized? To answer this, current study has borrowed the argument of Khan (1987) who explain the same thing in another area of social sciences much related to strategy in the business realm, i.e., economics. According to him, this methodology should commit to a certain set of conditions so that it may be accepted as a valid research methodology for strategy. A sizable mention of these conditions is provided. First two conditions are the main focus here as they are related to the paradigm or philosophical layers of the research onion, while rest of the conditions have been introduced only from the perspective of practical utility of the proposed methodology. The number and the types of conditions is not limited to those as provided here. Author humbly acknowledges intellectual shortcomings on his part and believes that other researchers and intellectuals may come up with various ways of seeing the same thing but from different perspectives and suggest newer dimensions. Below is an account of those conditions which require the proposed methodology to commit to:

- It Should Operate Within the Framework of Revelation and Employ Human Reason:

The Islamic Law provides principles and a framework for human affairs in every domain of life. This includes rituals as well as everyday affairs. To act according to this framework, Islamic Jurisprudence is enacted to interpret and explain the Islamic Law and provide guidance on the practical ways. Islamic Jurisprudence extends the same framework of Islamic Law to the realm of the social sciences, the subject of strategy to be more specific here.

This framework would operate over two plans, i.e., the fixed plane and the variable plane. The basic function of methodology is to set an approach to reach the truth. In this pursuit, the proposed methodology should, as earlier said, always look into the fundamental sources of knowledge in Islam, i.e. the Quran and the Sunnah. Being divine in nature, the postulates from these sources are true and there arise no question of their truth or falsity. They require no verification, e.g., guidelines about good and bad, rights and obligations, permissions and prohibitions, recommendations and abominations in variety of real-life situations, descriptions of natural and human phenomena etc. From these sources, the jurists discover general principles and then apply those for verifying specific situations. Moreover, they develop a framework of guidelines which help everyone who encounters real life situations and tries to act within such framework. These sources, the principles and the framework that springs out of these are accepted as true and belong to the 'fixed plane' of the research methodology.

At the same time, these sources, the principles and the framework are the criteria for testing theories propounded by human beings. Any theory put forward by a human being is tested on these criteria and if there is a clear and undeniable contradiction, the theory is rejected straight away without any further examination. In some cases, it may be possible that those testing the theory are not able somehow to grasp the exact meaning of the given text. So further investigation and findings may change the existing standpoint. 
A delicate but extremely important distinction must be kept in mind. Texts are divine but the human interpretation of these text is not divine, especially in those areas where affairs of life change with time-space-people domain changes. The human interpretation of these texts is open to examination and criticism and is the subject of discussion falling under certain set of principles in the field of Jurisprudence known as the principles of jurisprudence (Usul al Figh) and the legal maxims (Qawaid Fiqhiyyah) to derive inferences from these texts and their judgments. The methodology would always take these established principles in considerations in the process of theory building, testing and implementing the theory etc. This is the 'variable' or 'flexible plane' of the Islamic Law.

It is important to emphasize the importance of reviewing the body of literature of Islamic Jurisprudence, especially that which is concerned with collective spheres of human life, that has been developed and accumulated over centuries and let the Ijtihad be performed to see what aspects of the existing literature may need to be updated or upgraded to cope with the challenges that have arose over time-space-people changes. This can be done to what extent? It is a topic of hot debate among scholars of Islamic Jurisprudence but we leave this for the sake of focusing on current study. Those interested in this aspect may look into the works of Codd (1999) and Tueni (2015) etc. for a better understanding of the subject matter.

The fixed aspect of the methodology operates in limited amplitude in response to certain questions or situations. The dominant part of the methodology requires application of human reason and intellect within the over-all divine framework. The question of methodology becomes imminent mainly in the area where human reason is applied. In this area the general principle is that if a theory does not contradict any divine text it would be open for criticism. The criticism would be on two planes: rational plane as well as empirical plane. A theory must satisfy both the criteria. It should be true on rational grounds and should also be confirmed by empirical evidence. The confirmation is sought by Popperian thesis of falsification. It means that a theory would be tested on the criterion of falsifiability. The theories which are not falsified by these two criteria would be accepted.It further implies that the hypotheses, of methodology in Islamic context, must be stated in a form that they can be falsified. In other words, the hypothesis must make clear its conditions and predictions. A hypothesis would merit consideration only if it tells the situation in which it would not hold or if it specifies the conditions which would falsify.

- It Should Benefit from Inductive, Deductive and Abductive Approaches:

Methodology should be able to benefit from inductive, deductive, abductive reasoning instead of binding itself to one specific method.

Muslims are the inventors of the inductive reasoning as acknowledged by Draper (1875). In the pre-Islamic history, different cultures produced some great systems of philosophy but they were based on abstract speculative reasoning. The Quran invited people to observe, to look and see, to ponder. It argued on the evidence of such natural phenomena as sun, moon, day, night, rainfall, seasons, differences of colors and tongues, human creation etc. This ignited a spirit of inquiry which led to the discovery of inductive method in research. The Quran cites the example of Prophet Abraham PBUH who asked for an empirical evidence for life after death. Allah has used the experimental method to establish validity of metaphysical truths at times. It shows that for physical reality, it would be still more preferable to hold on to this method. Therefore, the inductive approach is embedded into the Muslim tradition and should be taken as a continuation of this tradition in present times. The concept of a priori argues that it is not possible to derive any scientific conclusions merely by inductive methods and claims that the real source of knowledge is the human intellect and not necessarily the observation itself. This argument bears good weightage but it is not all encompassing. It should be noted that in addition to human intellect there are other sources of knowledge as well, e.g., revelation and intuition etc. Also, human mind is capable of receiving flashes of brilliant ideas which do not have any visible linkages in the empirical world or which are not result of systematic observation. The point to make here is that the source of a theorem may be inductive or a priori; but the methodology tests it on multiple criteria of Islamic Law, reason and empirical-evidence.

In regard to deductive reasoning, empiricist question the validity of the assumption of perfect knowledge as exhibited by the deductive reasoning. The assumption of perfect knowledge cannot be accepted as it clashes with one of the fundamental beliefs of Islam. Perfect knowledge of the future is only with Allah and man has only an imperfect knowledge. Therefore, the method of abstract deductions on the assumption of perfect knowledge cannot be acceptable. To summarize the whole argument, it can be said that: From Islamic perspective, human intellect is accepted as a valid source of knowledge but model building is not accepted on the basis of mere deductive reasoning. This is because model building involves a chain of deductions 
from initial premises which presumes perfect knowledge of the future. A serious question arises then: how may a methodology proceed to model building? A possible way to cope with this question could be to modify the theme entailed within the cause-effect relation from 'definitive' to 'probable' assumption on both sides of the logical arguments; and once a result is arrived at, it should be tested by quantitative and qualitative data and techniques. Another alternative could be to understand human behavior at individual and group levels in the historical and institutional settings and then hypothesize something on the basis of actual existing knowledge. This would require adoption of unusual research methods borrowed from such disciplines as sociology, marketing, social psychology, social anthropology, history, economics, and industrial relations and even neuro sciences, chemical processes, genetics etc. because all these have a role in shaping complex human behavior in individual and in group settings.

There is another approach known as abductive reasoning. According to Suddaby (2006) an abductive approach moves back and forth, combining deduction and induction while differs from both the induction (data to theory) and deduction (theory to data). It's quite common among researches and practitioners. It begins with the observation of a 'surprising fact'; it then works out a plausible theory of how this could have occurred. Van Maanen et al. (2007) noted that some plausible theories can account for what is observed better than others and it is these theories that will help uncover more 'surprising facts'. These surprises, they argue, can occur at any stage in the research process. Van Maanen et al. also stress that deduction and induction complement abduction as logics for testing plausible theories. If this approach is employed, arguably, it has the potential to overcome the contradiction (claim of the perfect knowledge) which deduction offers when one operates in a setting proposed by methodology from Islamic perspective.

The study argues that incorporating these approaches into research methodology from Islamic perspective is a challenging objective and needs to be dealt with extreme care. This is because the adopted approach(es) would be acting at behalf of the Islamic Law through Islamic Jurisprudence and weaving the whole fabric to ensure that the whole methodology is operating in a homogeneous and coherent manner (Hassan, 2016). On one side it would be receiving its legitimacy from the Islamic Law, and on the other hand it would be moderating and orchestrating the other organs of the research methodology such as data collection, data analysis etc. And at the same time, making the flow of Islamic value system throughout this fabric.

\section{- It Should Focus on Problem-Solving}

The concept of strategy has always existed in the Islamic sources of knowledge (Gul, 2016) and in the Islamic cultures with different names, however, it never existed as a separate subject area for research. This came to fore, as a social science, from the Western cultural contexts to cope with the organizational and management issues. While an attempt is being made to propose a methodology for this concept from an Islamic perspective, it is emphasized that proposed methodology should also be able to focus on real issues of the strategy in theoretical as well as practical realms. It should be able to contribute to resolving issues popping-up in theory testing and model building. Also, it should serve to solve the organizational and management issues on ground. In doing so it should focus to understand the strategy, strategy formulation and implementation, and strategic decision-making process etc. It should be able to correlate human behavior, work process, technology, atmosphere, i.e., maximum number of phenomena or variables. This will help generate theories and models for the ultimate interest of owners, employees, participants, clients, citizens and the society at large, however, within the paradigm in which it operates.

- It Should be Internally Consistence and Coherent:

There should not exist a disconnect among the layers of the Research Onion as proposed from Islamic perspective. It should be internally consistent and coherent while operating to find the truth both ways, i.e. from the fundamental paradigm and world-view down the path to the data collection and analysis techniques. If this consistency and coherence is missed, then the proposed methodology won't qualify to be a valid methodology, rather it would be just like welding different metals with each other without going through real chemical reaction to produce a deemed homogenous product.

- It Should Be Open for Criticism:

This methodology would be open to examination by anyone, i.e., Muslims and non-Muslims alike. It is ultimately the weight of its arguments and the rigor of its analysis that would fetch merit. Therefore, it should avoid to being in a closed cell. It should devote greater attention to the analysis and solution of the present-day problems rather than recount the glory of Islam which it once was. It does not mean that it should discard historical perspective but it only means that historical data needs be used to learn lessons for the present rather than to merely rejoice in the trance of glorification. 


\subsection{Final Comments}

It can be safely argued now that a methodology could be proposed which appears to be similar in structure to the one as developed in the Western cultures, however, with different paradigm and philosophy. In present case, the Tawhidic paradigm and the Islamic Law (Interpreted and extended through Islamic Jurisprudence) would serve as the research philosophy while Islamic logic approach as the research approach(es). When this methodology would intrinsically exhibit the characteristics as prescribed in the previous section, staying within the framework defined by Islamic Law, meets the criteria of reason and empirical validity, then it may be referred to as research methodology for strategy. A methodology that springs from Islamic sources of knowledge or put simply, methodology from Islamic perspective. A methodology which stands to be testified in real organization and management scenarios, e.g., corporate strategy, communication strategy, human resource development strategy etc.

\section{Conclusions, Limitations and Future Research}

- Like other areas of knowledge and practice, the field of strategy is developing itself with newer ways to cope with the problems that arise in organization and management realm. Research methodology from Islamic perspective, provided it passes the qualifications to be a methodology, may offer its contributions to enrich this area further to overcome such problems.

- If this could lead to plausible solutions to issues, it would be accepted by the world, whatever its method of inquiry be. For the business world in general, it is not the method of inquiry that is important, it is the contribution that this methodology can make in terms of the weight of its arguments and the rigor of its analysis.

- This methodology needs not be confined to any one method. Rather it should remain open to all methods provided the inquiry remains within the basic framework as prescribed by Islamic Law and it is satisfying, at least, the twin criteria of reason and empirical validity.

- Author admits incapability to choose a specific name for the proposed methodology and contents to use the phrase 'research methodology from an Islamic perspective'. At the same time, author considers to let it be open for examination by anyone whatever be the religious or cultural background of the researcher.

- This methodology should focus on analysis of the problems and their solutions instead of merely claiming that 'this already exists in Islam'.

- This methodology has yet to be tested and verified. It may be accepted or rejected fully or partially. Moreover, its comparison with the one in Western cultural context is also a subject of a separate study.

- Another aspect which needs to be considered is the condition of presence of an Islamic state for the successful implementation of such a methodology.

\section{References}

Azram, M. (2011). Epistemology - An Islamic Perspective. IIUM Engineering Journal, 12(5), 179-187. https://doi.org/10.31436/iiumej.v12i5.240

Bryman, A., \& Bell, E. (2007). Business research methods. 2nd Edition. Oxford: Oxford University Press

Burrell, G., \& Morgan, G. (1979). In Sociological Paradigms and Organizational Analysis. Exeter: NH, Heinemann. (HC).

Codd, R. A. (1999). A Critical Analysis of the Role of Ijtihad in Legal Reforms in the Muslim World. Arab Law Quarterly, 14(2). https://doi.org/10.1163/026805599125826354

Crotty, M. (1998). The Foundations of Social Research. London: Sage.

Denffer, A. V. (1994). Ulum al Quran: An introduction to the sciences of the Qur'ān. Leicester: The Islamic Foundation.

Draper, J. W. (1875). History of the Conflict between Religion and Science. NEW YORK: D. APPLETON AND COMPANY, 549 \& 551 BROADWAY.

Easterby-Smith, M., Thorpe, R., Jackson, P., \& Lowe, A. (2012). Management Research. $4^{\text {th }}$ Edition. London: Sage.

Hassan, S. A. (2016). The Use of Logic in Contemporary Islamic Discourses. Mediterranean Journal of Social Sciences, 7(5), 171-179. https://doi.org/10.5901/mjss.2016.v7n5p171

Kazmi, A. (2003). Proposed research agenda in Islamic perspectives on management studies. IIUM Journal of Economics and Management, 11(2), 197-227. 
Kazmi, A. (2005). Probable differences among the paradigms governing conventional and Islamic approaches to management. Int. J. Management Concepts and Philosophy, 1(4), 263-289. https://doi.org/10.1504/IJMCP.2005.008529

Kazmi, A. (2008). Strategic management \& business policy. New Delhi: Tata McGraw-Hill Publishing Company Limited.

Kazmi, A., \& Ahmad, K. (2006). Management from Islamic perspective. Kuala Lumpur: International Islamic University of Malaysia Press.

Ketchen Jr, D. J. K, Boyed, B. K., Brian K. B, Donald D., \& Bergh, D. D. (2008), Research Methodology in Strategic Management: Past Accomplishments and Future Challenges. Organizational Research Methods, 11(4), 643-658. https://doi.org/10.1177/1094428108319843

Khan, M. A. (1987). Methodology of Islamic Economics. Journal of Islamic Economics, 1(1), 17-33.

Kuhn, T. S. (1962). The Structure of Scientific Revolutions. Chicago: University of Chicago Press. (HC).

March, J. (2007). The study of organizations and organizing since 1945. Organization Studies, 28(1), 9-19. https://doi.org/10.1177/0170840607075277

Maududi, S. A. (2013). Islamic Civilization: Foundational Beliefs and Principles. Islamabad: IPS Press.

Miller, K. (2008). Simon and Polanyi on rationality and knowledge. Organization Studies, 29(7), 933-955. https://doi.org/10.1177/0170840608090532

Nieto, S. (1999). The light in their eyes: Creating multicultural learning communities. NY: Teachers College Press: Multicultural Education Series.

Nyazee, I. A. K. (2006). Islmic Jurisprudence. Islamabad, IIIT.

Nyazee, I. A. K. (2014). Theories of Islamic Law. Islamabad, International Islamic University.

Philips, Dr. A. B. (2007). Usool Al Hadeeth: The Methodology of Hadith Evaluation. $2^{\text {nd }}$ Edition. Riyadh: IIPH

Saunders, M., Lewis, P., \& Thornhill, A. (2009). Understanding research philosophies and approaches. Retrieved on $14^{\text {th }}$ April, 2019, from https://www.researchgate.net/publication/309102603_Understanding_research_philosophies_and_approach es

Suddaby, R. (2006). What grounded theory is not. Academy of Management Journal, 49(4), 633-643. https://doi.org/10.5465/amj.2006.22083020

Sutton, R. I., \& Staw, B. M. (1995). What Theory is Not. Administrative Science Quarterly, 40(3), 371-384. https://doi.org/10.2307/2393788

Tueni, T. B. (2015). Scope and Limits of Ijtihad for the Continued Evolution of Islamic Law. SOAS Law Journal, 2(2), 93-112

Van Maanen, J., Sørensen, J. B., \& Mitchell, T. R. (2007). The interplay between theory and method. Academy of Management Review, 32(4), 1145-1154. https://doi.org/10.5465/amr.2007.26586080

Weick, K. E. (1996). Drop your tools: An allegory for organizational studies. Administrative Science Quarterly, 4l(2), 301-313. https://doi.org/10.2307/2393722

Zandi, G. R., Joupari, N. Z. P., \& Aslam, A. (2015). The Strategies in the battles and Struggles of Muhammad: How It Can Be Applied in Modern Business. International Business Research, 8(11), 84-110. https://doi.org/10.5539/ibr.v8n11p84

\section{Copyrights}

Copyright for this article is retained by the author(s), with first publication rights granted to the journal.

This is an open-access article distributed under the terms and conditions of the Creative Commons Attribution license (http://creativecommons.org/licenses/by/4.0/). 